\title{
Trace element characteristics of garnet dunites/harzburgites, host rocks for Siberian peridotitic diamonds.
}

\author{
N. Shimizul', N. P. Pokhilenko², F. R. Boyd ${ }^{3}$, D. G. Pearson ${ }^{4}$,
}

1: Department of Marine Geology and Geophysics, Woods Hole Oceanographic Institution, 360 Wood Hole Rd, Woods Hole, MA 02540-1541, USA

2: United Institute for Geophysics and Mineralogy, Russian Acad. Sci., Novosibirsk

3: Geophysical Laboratory, Carnegie Institution of Washington

4: Department of Geological Sciences, University of Durham

Geochemical processes leading to the formation of peridotitic diamonds are still not clearly understood, partly because geochemistry of diamond host rocks is poorly known. In Siberian kimberlites, peridotitic diamonds occur in megacrystalline dunites/harzburgites (Sobolev, 1974; Pokhilenko et al., 1977; Sobolev et al., 1984) and their mineral chemistries (olivine, garnet, and occasional spinel and orthopyroxene) are very similar to those of diamond inclusions (e.g., Pokhilenko et al., 1991).

Isotopically, these rocks are characterized by unradiogenic Os $(\gamma$ ranges from -7.5 to -15$)$ and $\mathrm{Nd}(\varepsilon$ from -18.6 to -55.1$)$, demonstrating their ancient lithospheric provenance (Pearson et al., 1995).

The purpose of this study is to characterize garnets in megacrystalline dunites/harzburgites for trace element abundance patterns and distributions in order to establish a comprehensive dataset which can be compared with the growing volume of data of peridotitic garnet inclusions in diamonds (e.g., Shimizu et al., 1997).

Samples used are all from the Udachnaya kimberlite pipe. Some have been analyzed for Os (whole-rocks), and $\mathrm{Nd}$ and $\mathrm{Sr}$ (garnets) isotopes (Pearson et al., 1995). Some are diamond-bearing. Garnet in these rocks is finer-grained $(0.2-6 \mathrm{~mm}$ ) relative to olivine (up to $10 \mathrm{~cm}$ ), and frequently occurs in strings or layers. These rocks generally occur as small friable xenoliths, and in fact, some samples were available only in crushed form.

A Cameca IMS $3 \mathrm{f}$ ion probe at Woods Hole Oceanographic Institution was used to determine concentrations of Ti, V, Sr, Y, Zr, La, Ce, Nd, Sm, Eu, Dy, Er and Yb. Rare earth elements were determined with a spatial resolution of $\sim 30 \mu \mathrm{m}$, whereas other trace elements used a smaller beam size $(\sim 5 \mu \mathrm{m})$. All analyses were made with an energy offset of $-90 \mathrm{~V}$. Analytical uncertainties range from $10-30 \%$ for rare earth elements to $3-5 \%$ for other trace elements.

Important features observed are as follows:

(1) Trace element abundances and abundance patterns of subcalcic garnets in megacrystalline dunites are very similar to those of the peridotitic garnet inclusions in diamonds from Siberia. For instance, REE patterns are typically sinusoidal with $[\mathrm{La}]_{\mathrm{n}}<\sim 1$, maximum at $[\mathrm{Sm}]_{\mathrm{n}} \sim 5$, minimum at $[\mathrm{Dy}]_{\mathrm{n}}$ $\sim 0.8$ and $[\mathrm{Yb}]_{\mathrm{n}} \sim 2-5$

(2) Element correlations are quite variable from sample to sample and no systematic trends can be obtained;

(3) Grains are commonly zoned with respect to some elements with ranges of variations over a factor of 4 - 5 over distances of tens of micrometers;

(4) Individual grains in a given sample often display significant (up to a factor of 5) grain-by-grain heterogeneities.

These results suggest that garnets in megacrystalline rocks represent material environment and geochemical processes very similar to those for peridotitic garnet inclusions in diamonds. It was also observed that except for minor kelyphitic alteration there is no indication for chemical 
modification after crystallization. Zoning and grain-by-grain heterogeneities observed over short distances indicate that growth of garnet crystals occurred under highly non-equilibrium conditions. The results also suggest that garnets in these rocks formed shortly before eruption of kimberlite, similar to garnet inclusions in diamonds. Ancient model ages (Pearson et al., 1995) can be reconciled with young formation ages via fluid-assisted dissolution/precipitation mechanisms which mobilized and transported ancient lithospheric materials and precipitated garnet. This type of process may also explain characteristic occurrence of garnet in these rocks.

\section{References}

Pearson, D. G., Shirey, S. B., Carlson, R. W., Boyd, F. R., Pokhilenko, N. P. and Shimizu, N., 1995, $\mathrm{Re}-\mathrm{Os}, \mathrm{Sm}-\mathrm{Nd}$, and $\mathrm{Rb}-\mathrm{Sr}$ isotope evidence for thick Archaean lithospheric mantle beneath the Siberian craton modified by multistage metasomatism: Geochim. Cosmochim. Acta, 59, p. 959-977. Pokhilenko, N. P., Sobolev, N. V. and Larent'ev, Y. G., 1977, Xenoliths of diamondiferous ultramafic rocks from Yakutian kimberlites: Ext. Abst., Int. Kimb. Conf., Santa Fe.

Pokhilenko, N. P., Pearson, D. G., Boyd, F. R. and Sobolev, N. V., 1991, Megacrystalline dunites and peridotites: Hosts for Siberian diamonds, Carnegie Inst. Wash., Yearbook, 90-91, p. 11-18. Shimizu, N., Sobolev, N. V. and Yefimova, E. S., 1997, Chemical heterogeneities of inclusion garnets and juvenile character of peridotitic diamonds from Siberia, Russ. Geol. Geophys., 38, p. 356-372. Sobolev, N. V., 1974, Deep seated inclusions in kimberlites and problem of upper mantle compositions, 264 pp, Nauka, Novosibirsk.

Sobolev, N. V., Pokhilenko, N. P. and Yefimova, E. S., 1984, Diamond-bearing peridotite xenoliths in kimberlite and the problem of the origin of diamonds, Sov. Geol. Geophys., 25, p. 62-76. 